\title{
The effect of birth weight on glucose tolerance in pigs at 3 and 12 months of age
}

\author{
K. R. Poore, A. L. Fowden \\ Department of Physiology, University of Cambridge, Downing Street, Cambridge, UK
}

\begin{abstract}
Aims/hypothesis. The aim of this study was to examine the effect of birth weight on glucose tolerance in juvenile and adult pigs.

Methods. Low $(<1.47 \mathrm{~kg})$ and high $(>1.53 \mathrm{~kg})$ birth weight piglets from 15 litters were studied at $3(n=47)$ and $12(n=17)$ months of age. At each age, selected pigs were tranquilised and catheters were inserted into the dorsal aorta and caudal vena cava under general anaesthesia. After recovery, glucose $(0.5 \mathrm{~g} / \mathrm{kg}$; i.v. $)$ was administered and regular arterial blood samples were taken for $2 \mathrm{~h}$ for plasma glucose and insulin measurements. Hepatic gluconeogenic enzyme activities were measured at post mortem.

Results. At 12, but not at 3 months of age, the area under the glucose and insulin curves after glucose
\end{abstract}

administration were greater $(p<0.05)$ in low rather than in high birth weight pigs. The glucose area at 12 months was negatively correlated with body weight and BMI at birth. Disproportionate shape at birth was associated with reduced hepatic gluconeogenic enzyme concentrations and low birth weight pigs had reduced basal glucose concentrations at 12 months of age.

Conclusion/interpretation. This study has shown an association between low birth weight and thinness at birth and glucose intolerance at 12 months of postnatal age, but not at 3 months. This effect was not due to insulin deficiency or increased hepatic gluconeogenic enzyme activity. [Diabetologia (2002) 45:1247-1254]

Keywords Intra-uterine programming, low birth weight, glucose tolerance, pigs.
Epidemiological studies have shown that low birth weight (BW) is associated with an increased risk of metabolic diseases such as glucose intolerance, insulin resistance and Type II (non-insulin-dependent) diabetes mellitus in adult life $[1,2]$. These associations have now been described in several human popula-

Received: 9 October 2001 / Revised: 7 March 2002

Published online: 4 July 2002

(C) Springer-Verlag 2002

Corresponding author: Dr. K. R. Poore, Centre for Fetal Origins of Adult Disease, University of Southampton, Princess Anne Hospital, Level F (MP 887), Southampton, SO16 5YA, UK, E-mail: kpoore@ soton.ac.uk

Abbreviations: AC, Abdominal circumference; AUC, area under the curve; BW, birth weight; $\mathrm{CW}$, current weight; G6Pase, glucose-6-phosphatase; FGR, fractional growth rate; GR, growth rate; GTT, glucose tolerance test; $\mathrm{m}$, month; PEPCK, phosphoenolpyruvate carboxykinase; $\mathrm{t}^{1} /{ }_{2}$ half-life tions of different ages, sex and ethnic origin [3]. Anthropomorphic measurements have shown that disproportionate foetal growth leading to a low ponderal index (weight/length ${ }^{3}$ ), or reduced head circumference to body length ratio at birth, particularly predisposes the individual to poor glucose tolerance in later life [2]. These observations have led to the hypothesis that impaired glucose tolerance might originate in foetal life as the result of intrauterine tissue programming by environmental influences acting at critical stages of early development [4].

Prenatal nutritional programming of adult glucose intolerance has also been reported in several experimental animals including rodents, guinea pigs and sheep [5,6]. Detailed investigation of physiological mechanisms mediating the association between poor glucose tolerance in postnatal life and low BW has proved difficult in species such as rats and guinea pigs because the small size of the neonates limits physio- 
logical investigation during early postnatal life. The sheep is larger but the nature of ruminant digestion means it is difficult to regulate nutrient intake postnatally. In contrast, piglets are large enough to study from birth and nutrient availability can be regulated precisely after weaning. In addition, BW varies two to threefold amongst littermates in normally fed sows which provides a naturally occurring form of growth retardation with less genetic variation than seen in humans and other monotocous species. Hence, the aims of this study were to determine the long-term consequences of natural variations in BW in pigs on: i) basal glucose concentrations and glucose tolerance following an intravenous glucose challenge; ii) basal and glucose-stimulated insulin concentrations; and iii) hepatic gluconeogenic enzyme activity. Pigs were studied as juveniles ( 3 months) and as adults (12 months of postnatal age). A preliminary account of some of these observations has been published previously [7].

\section{Materials and methods}

Animals. Pure-bred pigs were obtained from sows (Large White Breed) which were allowed to farrow normally at term (115 \pm 2 days). Fifteen litters from nine sows were used in this study. Sows were fed a standard diet $(15 \%$ protein; $12.6 \mathrm{MJ} / \mathrm{kg}$ digestible energy; ABN, Peterborough, UK) at least 4 weeks prior to conception $(2 \mathrm{~kg}$ /day) and during gestation and lactation (2.5 to $3 \mathrm{~kg} /$ day) according to standard guidelines [8]. Water was provided ad libitum. Piglets were provided with straw bedding and infrared heat lamps from birth until weaning at 4 to 5 weeks of age. Weaner piglets were housed in groups and fed ad libitum on a standard pig creep diet (20\% protein; $\mathrm{H} \& \mathrm{C}$ Beart, Kings Lynn, UK) until the first studies at 3 months of age. Pigs were then housed individually adjacent to their siblings and fed according to their size $(0.5 \mathrm{~kg}$ per $30 \mathrm{~kg}$ body weight, twice daily; [8]). After all the 3-month-old studies, they were returned to group housing (ad libitum feeding of $20 \%$ protein pig creep) until at age 4 to 5 months (prior to puberty) they were again housed individually and fed on the adult $15 \%$ protein diet for the remainder of the study.

At birth, all piglets in each litter were weighed and head length (snout to between the ears), crown rump length and abdominal circumference (AC) measurements were made. The average BW of all piglets for this study was $1.50 \pm 0.02 \mathrm{~kg}$ $(n=170 ; 15$ litters $)$ and the $95 \%$ CI of the mean was 1.47 to $1.53 \mathrm{~kg}$. After BW was measured, pigs were assigned to one of two groups, those with BW lower than $95 \%$ CI of the mean $\mathrm{BW}$ were defined as 'low BW' pigs $(<1.47 \mathrm{~kg}$ at birth) and those higher than $95 \% \mathrm{CI}$ of the mean BW were defined as 'high $\mathrm{BW}$ ' pigs (>1.53 kg at birth). The range of birth weights in the low BW group was $0.80-1.40 \mathrm{~kg}(n=22)$ and in the high BW group was $1.65-2.40 \mathrm{~kg}(n=25)$. Approximately similar numbers of each sex were selected (low BW females, $n=15$; low BW males, $n=7$; high BW females, $n=13$; high BW males, $n=12$ ). Selected pigs were weighed and measured again at 1,3 and 12 months of age. It was not possible to obtain all data from all animals.

At 9 to 10 weeks of age, before the morning feed, selected pigs were tranquilised with azaperone (Janssen Pharmaceuticals, Oxford, UK; $5 \mathrm{mg} / \mathrm{kg}$ i.m. for pigs $>20 \mathrm{~kg}$ ) or diazepam (Phoenix Pharmaceuticals, Gloucester, UK; $2 \mathrm{mg} / \mathrm{kg}$ i.m. for pigs $<20 \mathrm{~kg}$ ), each in combination with ketamine (Fort Dodge
Animal Health, Southampton, UK; $10 \mathrm{mg} / \mathrm{kg}$ i.m.) and then anaesthetised with halothane $\left(3-6 \%\right.$ in $\left.\mathrm{O}_{2}\right)$. Catheters were inserted into the dorsal aorta and vena cava via the femoral vessels and exteriorised via a small incision on the animal's back. Pigs were kept in protective coats made of elastic tubing (Tubigrip, Seton Healthcare Group, Oldham, UK) to protect the catheters. Antibiotic treatment was administered on the day of surgery (Depocillin; procaine benzylpenicillin, $15 \mathrm{mg} / \mathrm{kg}$; Depocillin Mycofarm, Cambridge, UK and Duphatrim; trimethoprim, $2.5 \mathrm{mg} / \mathrm{kg}$ with sulfadiazine, $12.5 \mathrm{mg} / \mathrm{kg}$; Fort Dodge Animal Health; i.m.), for 3 days following surgery and every 2 to 3 days thereafter (Duphatrim alone, i.v.). The normal feeding regime was restored immediately after recovery from surgery.

Seventeen pigs had their catheters and protective coats removed at the completion of the experiments at 3 months of age and were studied again at 10 to 12 months of age (low BW females, $n=5$; low $\mathrm{BW}$ males, $n=4$; high $\mathrm{BW}$ females, $n=4$; high BW males, $n=4)$. Femoral artery and vein catheters were inserted in the previously unoperated leg under general anaesthesia (sodium pentobarbitone, Rhône Mérieux, Harlow, UK; $20 \mathrm{mg} / \mathrm{kg}$ i.v.) following tranquilisation with azaperone ( $5 \mathrm{mg} / \mathrm{kg}$ i.m.).

All procedures were carried out in accordance with the regulations of the UK Home Office Animals (Scientific Procedures) Act, 1986.

Experimental Protocol. Two days after surgery, a glucose tolerance test (GTT) was carried out after an overnight fast. Glucose $(0.5 \mathrm{~g} / \mathrm{kg}$ body weight $)$ was administered as a bolus intravenous dose at time 0 and arterial blood samples $(2 \mathrm{ml}$ into chilled EDTA tubes) were collected for analysis of plasma glucose and insulin concentrations at 30,15 min and immediately (0 min) before and 5, 10, 15, 20, 30, 45, 60, 90 and 120 min after glucose administration. All blood samples were centrifuged immediately for $5 \mathrm{~min}$ at $4^{\circ} \mathrm{C}$ and, after measurements of plasma glucose concentrations, plasma was stored at $-20^{\circ} \mathrm{C}$. For each GTT experiment, the areas (AUC) under the glucose and insulin response curves (integrated plasma concentrations after glucose administration (from 5-120 min) above the mean preGTT concentrations (from $-30-0$ min) were calculated. To calculate the glucose half-life $\left(\mathrm{t}^{1} / 2\right)$ an exponential decay curve was fitted to the glucose concentrations during the GTT $(5-120 \mathrm{~min})$ and the $\mathrm{t}^{1 /} / 2$ was given by $0.69 \times \mathrm{b}^{-1}$, where [glucose $]=$ peak [glucose $] \times \mathrm{e}^{-\mathrm{b}(\text { time })}+$ basal [glucose].

Tissue collection. At the end of the experimental period at 3 months of age, samples of liver were collected from pigs not required for adult studies (low $\mathrm{BW}, n=15$; high $\mathrm{BW}, n=10$ ) after being killed by the administration of a lethal dose of sodium pentobarbitone. Liver samples were frozen immediately in liquid nitrogen and stored at $-80^{\circ} \mathrm{C}$ for analysis of tissue gluconeogenic enzyme activity. Tissues were also collected from adult pigs at the end of the 12-month-old experimental period (low BW, $n=10$; high BW, $n=5$ ).

Biochemical analyses. Plasma glucose concentrations were measured using an automated analyser (Yellow Springs 2300 Stat Plus Glucose Lactate analyser; YSI, Farnborough, UK) and plasma insulin concentrations by a commercially available radioimmunoassay kit (INSIK-5; Diasorin, Wokingham, UK). The inter-assay and intra-assay coefficients of variation for the insulin assay were $10 \%$ and $8 \%$, respectively. Basal glucose and insulin concentrations for each animal were each given by the means of two to three fasted samples taken on separate days.

Liver samples were assayed for glucose-6-phosphatase (G6Pase; EC 3.1.3.9) and phosphoenolpyruvate carboxykinase 
Table 1. Body weights, morphometric measurement ratios [at birth and at 3 and 12 months (m) of age] and postnatal growth rates in low and high body weight pigs

\begin{tabular}{lcc}
\hline & Low BW & High BW \\
\hline At birth: & & \\
BW (kg) & $1.13 \pm 0.04^{\mathrm{d}}$ & $1.90 \pm 0.04$ \\
BMI (kg/CRL $\left.{ }^{2}\right)$ & $17.7 \pm 0.31^{\mathrm{d}}$ & $21.4 \pm 0.51$ \\
Head length:BW (cm/kg) & $8.78 \pm 0.36^{\mathrm{d}}$ & $5.73 \pm 0.14$ \\
Head length:AC & $0.449 \pm 0.017^{\mathrm{a}}$ & $0.403 \pm 0.010$ \\
& & \\
At 3 months: & & \\
CW (kg) & $23.5 \pm 1.9^{\mathrm{d}}$ & $37.2 \pm 2.5$ \\
BMI (kg/CRL 2$)$ & $40.9 \pm 2.4^{\mathrm{a}}$ & $51.6 \pm 2.7$ \\
Head length:CW (cm/kg) & $0.99 \pm 0.09^{\mathrm{a}}$ & $0.63 \pm 0.08$ \\
Head length:AC & $0.339 \pm 0.014^{\mathrm{a}}$ & $0.303 \pm 0.010$ \\
& & \\
At 12 months: & & \\
CW (kg) & $152.8 \pm 8.1$ & $169.4 \pm 6.9$ \\
BMI (kg/CRL $\left.{ }^{2}\right)$ & $81.5 \pm 3.8$ & $82.0 \pm 5.9$ \\
Head length:CW (cm/kg) & $0.223 \pm 0.016$ & $0.260 \pm 0.032$ \\
Head length:AC & $0.268 \pm 0.015$ & $0.331 \pm 0.042$ \\
Postnatal growth rates: & & \\
GR 0-1 m (kg/day) & $0.237 \pm 0.012^{\mathrm{d}}$ & $0.350 \pm 0.014$ \\
GR 0-3 m (kg/day) & $0.284 \pm 0.020^{\mathrm{d}}$ & $0.452 \pm 0.030$ \\
GR 0-12 m (kg/day) & $0.476 \pm 0.034$ & $0.541 \pm 0.025$ \\
FGR 0-1 m (kg/day/kg) & $0.175 \pm 0.008^{\mathrm{b}}$ & $0.144 \pm 0.009$ \\
FGR 1-3 m (kg/day/kg) & $0.046 \pm 0.003$ & $0.056 \pm 0.003$ \\
FGR 3-12 m (kg/day/kg) & $0.026 \pm 0.002^{\mathrm{c}}$ & $0.016 \pm 0.002$ \\
\hline
\end{tabular}

Values are means \pm SEM. Low BW vs high BW (unpaired Student's $t$ test):

${ }^{\mathrm{a}} p<0.05 ;{ }^{\mathrm{b}} p<0.01 ;{ }^{\mathrm{c}} p<0.005 ;{ }^{\mathrm{d}} p<0.001$

At 3 months: low BW, $n=22$; high $\mathrm{BW}, n=25$. At 12 months: low BW, $n=9$; high BW, $n=8$

(PEPCK; EC 4.1.1.32) using established methods [9]. G6Pase and PEPCK activities were measured in whole liver homogenates, in duplicate, and enzyme activity was expressed in terms of units per $g$ of protein as measured by the Lowry method [10].

Statistics. All results are expressed as means \pm SEM. The associations between two factors were tested using linear regression analysis. The effects of group, time and age were tested using multifactorial analyses of variance (ANOVA). Where appropriate, Tukey posthoc tests were applied to identify statistically significant differences between means. Statistical analyses were carried out using Sigma Stat Statistical Software version 2.0. Unpaired Student's $t$ tests were used to identify differences between two factors. For all statistical tests, significance was accepted at a $p$ value of less than 0.05 .

\section{Results}

Postnatal growth. There were differences between low and high BW pigs in body weight, body mass index (BMI; weight/length ${ }^{2}$ ), head-length to currentweight $(\mathrm{CW})$ and head-length to $\mathrm{AC}$ at birth and at 3 months, but not at 12 months of age (Table 1). BW was positively associated with $\mathrm{CW}$ at 3 months $(r=0.48, n=47)$ but not 12 months of age. The head-
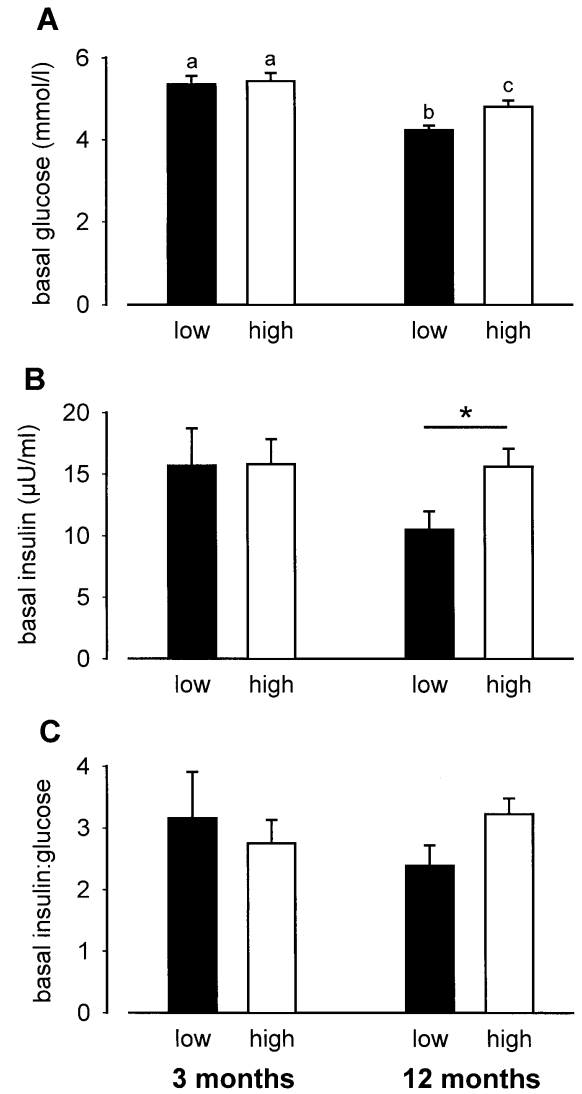

Fig. 1A-C. Basal plasma glucose (A) and insulin (B) concentrations and the basal insulin:glucose ratio $(\mathbf{C})$ in low $(\mathbf{\square})$ and high ( $\square$ ) BW pigs at 3 and 12 months of age. At 3 months: low $\mathrm{BW}, n=20$; high BW, $n=21$. At 12 months: low BW, $n=9$; high $\mathrm{BW}, n=8$. Different letters denote values that are significantly different from each other by two-way ANOVA for repeated measures. Bar indicates a significant difference between low and high BW pigs at 12 months only (Student's $t$ test)

length to body-weight and head-length to AC ratios at birth were also positively related between birth and 3 months ( $r=0.45, n=47$ and $r=0.50, n=47$, respectively), but not between birth and 12 months of age. Absolute postnatal growth rates (GR; $\mathrm{kg}$ gained/day) in low BW pigs from birth to 1 month and birth to 3 months of age were reduced compared with high $\mathrm{BW}$ pigs (Table 1). The relative increase in body weight (fractional GR; $\mathrm{kg}$ gained.day-1.starting $\mathrm{kg}^{-1}$ ) in low BW pigs was greater than in high $\mathrm{BW}$ pigs during suckling (birth to 1 month) and between 3 and 12 months of age, but not in the immediate post-weaning period (1 to 3 months; Table 1).

Basal insulin and glucose concentrations. At 3 months of age, there were no differences between low and high BW pigs in basal glucose, insulin or the ratio of basal insulin to basal glucose concentrations (Fig. 1A-C). Basal glucose concentrations were positively correlated to CW, GR (birth to 3 months) and fractional GR (1 to 3 months) and negatively correlated to current disproportionate body shape (head length:CW ratio; 
Table 2. Correlation coefficients $(r)$ between basal glucose and insulin concentrations at 3 and 12 months (m) and body weights, morphometric measurement ratios (at birth and at 3 and $12 \mathrm{~m}$ of age) and postnatal growth rates

\begin{tabular}{|c|c|c|c|c|c|c|}
\hline & \multicolumn{2}{|c|}{ Basal glucose } & \multicolumn{2}{|c|}{ Basal insulin } & \multicolumn{2}{|c|}{ Basal insulin:glucose } \\
\hline & $\begin{array}{l}3 \mathrm{~m} \\
\text { at birth: }\end{array}$ & $\begin{array}{l}12 \mathrm{~m} \\
\text { at birth: }\end{array}$ & $\begin{array}{l}3 \mathrm{~m} \\
\text { at birth: }\end{array}$ & $\begin{array}{l}12 \mathrm{~m} \\
\text { at birth: }\end{array}$ & $\begin{array}{l}3 \mathrm{~m} \\
\text { at birth: }\end{array}$ & $\begin{array}{l}12 \mathrm{~m} \\
\text { at birth: }\end{array}$ \\
\hline BW & +0.04 & +0.43 & +0.01 & $+0.53^{\mathrm{a}}$ & -0.06 & $+0.50^{\mathrm{a}}$ \\
\hline BMI & +0.004 & +0.33 & +0.04 & $+0.69^{b}$ & -0.07 & $+0.64^{b}$ \\
\hline Head length:BW & -0.19 & -0.29 & -0.02 & -0.27 & -0.05 & -0.30 \\
\hline & at $3 \mathrm{~m}$ : & at $12 \mathrm{~m}$ : & at $3 \mathrm{~m}$ : & at $12 \mathrm{~m}$ : & at $3 \mathrm{~m}$ : & at $12 \mathrm{~m}$ : \\
\hline CW & $+0.32^{\mathrm{a}}$ & +0.21 & +0.01 & +0.18 & -0.12 & +0.19 \\
\hline BMI & +0.19 & +0.06 & +0.21 & -0.09 & +0.16 & -0.01 \\
\hline Head length:CW & -0.50 a & +0.03 & -0.38 & +0.31 & -0.23 & +0.18 \\
\hline Head length:AC & -0.21 & +0.18 & $-0.47^{\mathrm{a}}$ & +0.40 & -0.39 & +0.18 \\
\hline FGR $1-3 \mathrm{~m}$ & $+0.36^{\mathrm{a}}$ & +0.40 & +0.02 & +0.15 & -0.11 & +0.13 \\
\hline FGR 3-12 m & - & +0.08 & - & -0.32 & - & -0.43 \\
\hline
\end{tabular}

a $p<0.05 ;{ }^{\mathrm{b}} p<0.005$

At 3 months: $n=41$; at 12 months: $n=17$
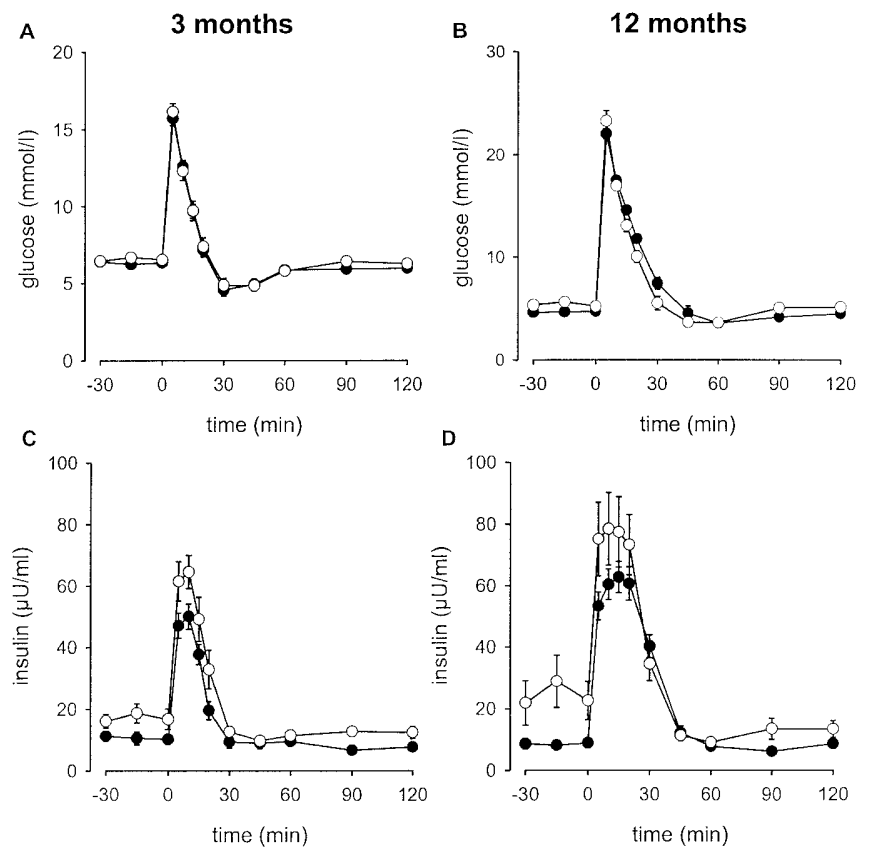

Fig. 2A-D. Plasma glucose $(\mathbf{A}, \mathbf{B})$ and insulin $(\mathbf{C}, \mathbf{D})$ concentrations following bolus intravenous administration of glucose $(0.5 \mathrm{~g} / \mathrm{kg}$ body weight; time 0$)$ in low $(\bigcirc)$ and high $(\bigcirc)$ birth weight pigs at $3(\mathbf{A}, \mathbf{C})$ and 12 months of age $(\mathbf{B}, \mathbf{D})$. At 3 months: low BW, $n=16$; high $\mathrm{BW}, n=14$. At 12 months: low $\mathrm{BW}, n=9$; high $\mathrm{BW}, n=7$. Glucose and insulin concentrations in all pigs were significantly increased following glucose administration at 3 and 12 months (A-D). At 3 months, insulin concentrations in low BW pigs were lower overall than in high $\mathrm{BW}$ pigs $(\mathbf{C})$. There was an interaction between time and group (low or high BW) on glucose (B) and insulin (D) concentrations at 12 months
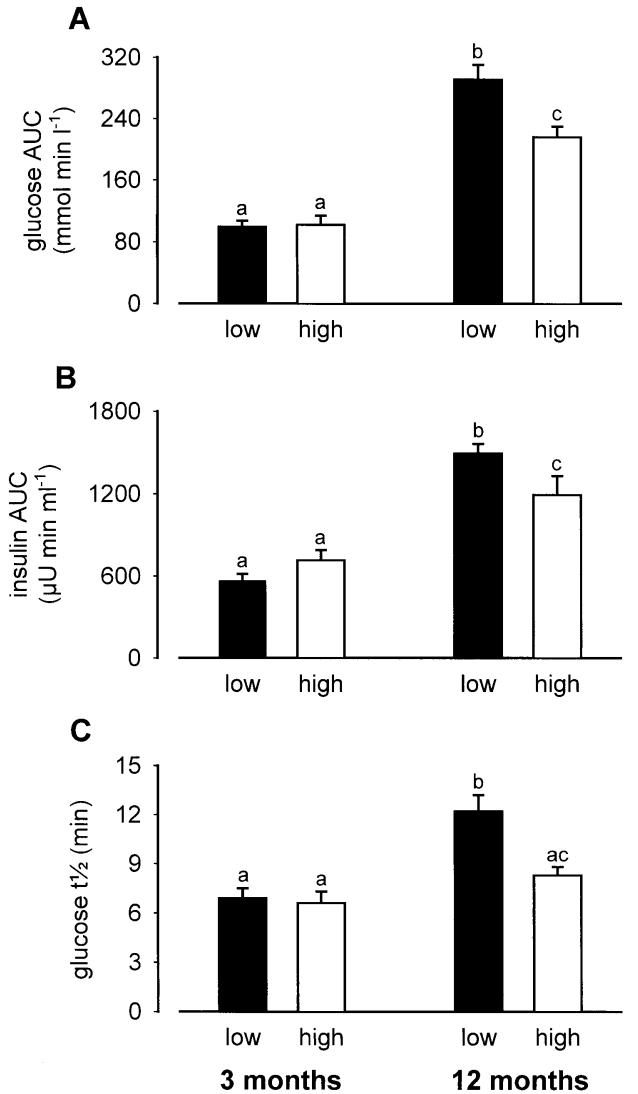

Fig. 3A-C. Area (AUC) under the glucose (A) and insulin (B) curves and the glucose $\mathrm{t}^{1 / 2}(\mathbf{C})$ following bolus intravenous administration of glucose $(0.5 \mathrm{~g} / \mathrm{kg}$ body weight $)$ in low (ם) and high ( $\square$ ) BW pigs at 3 and 12 months of age. At 3 months: low $\mathrm{BW}, n=16$; high BW, $n=14$. At 12 months: low BW, $n=9$; high $\mathrm{BW}, n=7$. Different letters denote values that are significantly different from each other by two way ANOVA for repeated measures 
Table 3. Correlation coefficients $(r)$ between area under the glucose and insulin curves (AUC) and glucose $\mathrm{t}^{1 / 2}$, during glucose tolerance tests at 3 and 12 months (m) and body weights, morphometric measurement ratios (at birth and at 3 and 12 months of age) and postnatal growth rates

\begin{tabular}{|c|c|c|c|c|c|c|c|c|}
\hline & \multicolumn{2}{|c|}{ Glucose AUC } & \multicolumn{2}{|c|}{ Insulin AUC } & \multicolumn{2}{|c|}{ Insulin AUC:glucose AUC } & \multicolumn{2}{|c|}{ Glucose $t^{1}$} \\
\hline & $\begin{array}{l}3 \mathrm{~m} \\
\text { at birth: }\end{array}$ & $\begin{array}{l}12 \mathrm{~m} \\
\text { at birth: }\end{array}$ & $\begin{array}{l}3 \mathrm{~m} \\
\text { at birth: }\end{array}$ & $\begin{array}{l}12 \mathrm{~m} \\
\text { at birth: }\end{array}$ & $\begin{array}{l}3 \mathrm{~m} \\
\text { at birth: }\end{array}$ & $\begin{array}{l}12 \mathrm{~m} \\
\text { at birth: }\end{array}$ & $\begin{array}{l}3 \mathrm{~m} \\
\text { at birth: }\end{array}$ & $\begin{array}{l}12 \mathrm{~m} \\
\text { at birth: }\end{array}$ \\
\hline BW & +0.04 & $-0.63^{b}$ & +0.33 & -0.41 & +0.32 & +0.16 & -0.07 & $-0.58^{a}$ \\
\hline BMI & -0.13 & $-0.51^{\mathrm{a}}$ & +0.29 & -0.27 & $+0.46^{\mathrm{a}}$ & +0.14 & -0.10 & -0.44 \\
\hline Head length:BW & +0.17 & $+0.61^{\mathrm{a}}$ & -0.20 & +0.39 & -0.34 & -0.26 & +0.34 & $+0.58^{a}$ \\
\hline Head length:AC & at $3 \mathrm{~m}$ : & at $12 \mathrm{~m}$ : & at $3 \mathrm{~m}$ : & at $12 \mathrm{~m}$ : & at $3 \mathrm{~m}$ : & at $12 \mathrm{~m}$ : & at $3 \mathrm{~m}$ : & at $12 \mathrm{~m}$ : \\
\hline $\mathrm{CW}$ & +0.20 & -0.13 & +0.28 & -0.29 & +0.13 & -0.10 & -0.02 & -0.06 \\
\hline BMI & +0.35 & -0.29 & +0.47 & -0.24 & +0.15 & +0.09 & +0.22 & -0.19 \\
\hline Head length:CW & -0.04 & +0.08 & -0.49 & +0.09 & -0.52 & -0.10 & +0.16 & +0.04 \\
\hline Head length:AC & +0.31 & -0.10 & +0.08 & -0.01 & -0.34 & +0.12 & +0.36 & -0.06 \\
\hline FGR $1-3 \mathrm{~m}$ & +0.11 & -0.25 & +0.17 & -0.29 & +0.13 & -0.22 & +0.02 & -0.15 \\
\hline FGR 3-12 m & - & +0.20 & - & +0.34 & - & +0.04 & - & +0.24 \\
\hline
\end{tabular}

a $p<0.05 ;{ }^{\mathrm{b}} p<0.01 ;{ }^{\mathrm{c}} p<0.005$

At 3 months: $n=30$; at 12 months: $n=16$

Table 2). Basal insulin concentrations at 3 months of age were negatively associated with current thinness (head length:AC ratio; Table 2).

At 12 months of age, basal glucose and insulin concentrations in low BW pigs were reduced and the ratio of basal insulin to basal glucose concentrations tended $(p=0.06)$ to be lower when compared to high $\mathrm{BW}$ pigs (Fig. 1A-C). Basal insulin concentrations and the basal-insulin to glucose ratio were positively associated with BW (Table 2). Basal glucose concentrations in 12-month-old pigs (low and high BW groups) were reduced compared to those at 3 months of age (Fig. 1A).

Glucose tolerance tests: glucose concentrations. At 3 months of age, the $\Delta$ peak (peak-mean basal) glucose concentrations achieved following glucose administration in low BW $(9.44 \pm 0.33 \mathrm{mmol} / \mathrm{l})$ and high BW $(9.59 \pm 0.54 \mathrm{mmol} / \mathrm{l})$ pigs were not different, nor were there any differences in glucose concentrations during the GTT overall (Fig. 2A). The area under the glucose curve (AUC) and the half-life $\left(\mathrm{t}^{1} / 2\right)$ of plasma glucose during the GTT were not different between low and high BW pigs (Fig. 3A, C). Glucose AUC at 3 months was not correlated to BW (Fig. 4A) or any other morphometric parameters (Table 3). Glucose AUC at 3 months was positively associated with fractional GR (0-1 month). The ratio of the insulin AUC:glucose AUC and glucose $\mathrm{t}^{1 / 2}$ were positively related to thinness (BMI) at birth (Table 3 ).

At 12 months of age, there was an interaction between the time and group (low or high BW) in glu- cose concentrations during the GTT, indicating a slower clearance of plasma glucose in the low BW group (Fig. 2B). The $\Delta$ peak glucose concentrations achieved in low BW $(17.35 \pm 0.50 \mathrm{mmol} / \mathrm{l})$ and high BW $(17.88 \pm 0.91 \mathrm{mmol} / \mathrm{l})$ pigs were not different (Fig. 2B). Glucose AUC and glucose $t^{1 / 2}$ in low BW pigs were greater than those in high $\mathrm{BW}$ pigs at 12 months (Fig. 3A, C). Glucose AUC at 12 months was negatively related to BW (Fig. 4B) and thinness at birth, and positively correlated to disproportionate shape at birth (Table 3). Glucose $t^{1 / 2}$ at 12 months of age was inversely associated with BW and positively associated with disproportionate shape at birth and fractional GR (birth to 1 month; Table 3). For both glucose AUC and glucose $t^{1} / 2$, there were effects of group and age and interactions between group and age, such that each parameter increased between 3 and 12 months of age, and, at 12 months, each was greater in low BW than high BW pigs (Fig. 3A,C). At 3 and 12 months of age, the effect of BW on postnatal glucose tolerance was similar in male and female pigs.

Glucose tolerance tests: insulin concentrations. At 3 months of age, plasma insulin concentrations during the GTT overall were reduced in low BW pigs, however the increase in insulin concentrations with time was not different between low and high BW pigs (Fig. 2C). There were no differences in the ratio of insulin AUC to glucose AUC at 3 months between low BW (6.06 \pm 0.67$)$ and high BW pigs $(7.68 \pm 0.76)$ or in the insulin AUC (Fig. 3B). The insulin AUC to glucose AUC ratio was positively associated with thinness at birth (Table 3). 
A

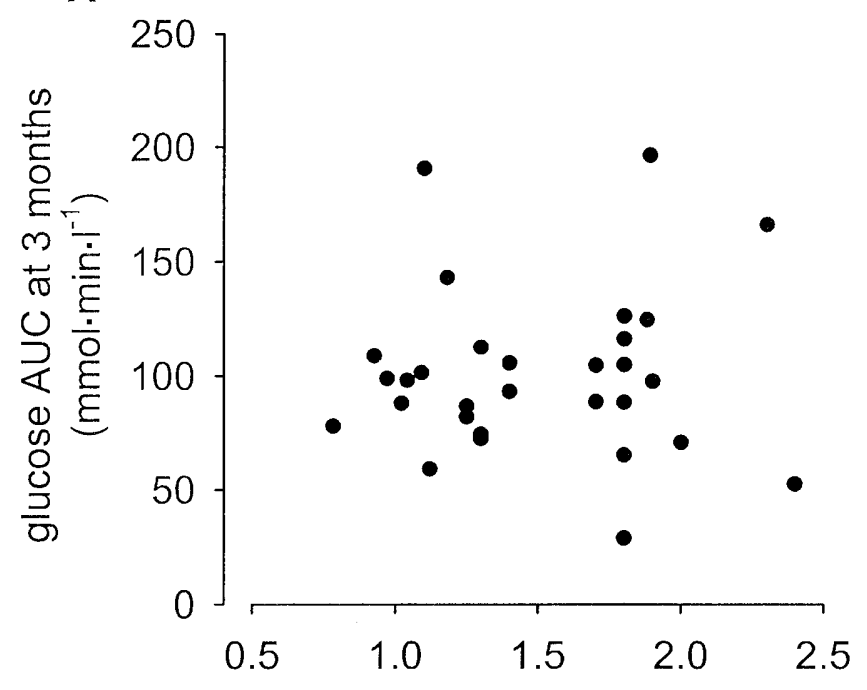

B

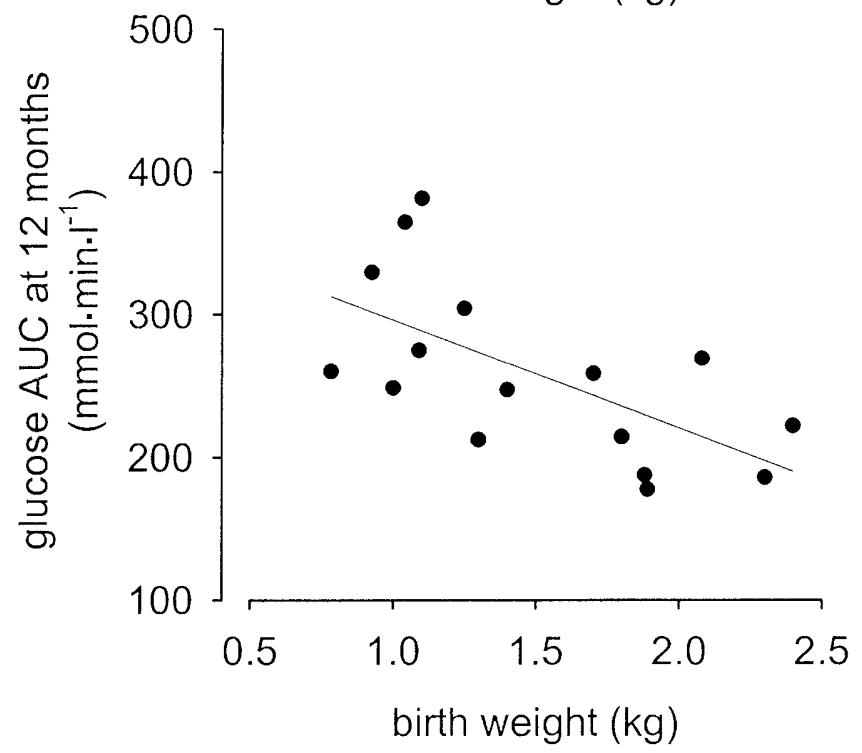

Fig. 4A, B. The associations between the area (AUC) under the glucose curve and birth weight following bolus intravenous administration of glucose $(0.5 \mathrm{~g} / \mathrm{kg}$ body weight $)$ at $3(\mathbf{A} ; n=30)$ and 12 months of age $(\mathbf{B} ; n=16)$. B; AUC=371.3-75.3 $\times \mathrm{BW}$; $r=0.63$

At 12 months of age, there was no effect of group on insulin concentrations during the GTT, however an interaction between time and group was found (Fig. 2D). Insulin AUC in 12 month-old low BW pigs was greater than that in high BW pigs (Fig. 3B). There was a negative association between insulin AUC at 12 months and GR (birth to 3 months; Table 4). There were no differences in the ratio of insulin AUC to glucose AUC at 12 months between low BW (5.25 \pm 0.32$)$ and high BW (5.59 \pm 0.74$)$ pigs.

Insulin AUC (low and high BW groups) increased from 3 to 12 months of age and there was an interaction between age and group (Fig. 3B). There were no effects of age or group on the insulin AUC to glucose AUC ratio.
Table 4. Correlation coefficients $(r)$ between hepatic gluconeogenic enzyme activities at 3 and 12 months (m) and body weights, morphometric measurement ratios (at birth and at 3 and $12 \mathrm{~m}$ of age) and postnatal growth rates

\begin{tabular}{|c|c|c|c|c|}
\hline & \multicolumn{2}{|c|}{ G6Pase activity } & \multicolumn{2}{|c|}{ PEPCK activity } \\
\hline & $\begin{array}{l}3 \mathrm{~m} \\
\text { at birth: }\end{array}$ & $\begin{array}{l}12 \mathrm{~m} \\
\text { at birth: }\end{array}$ & $\begin{array}{l}3 \mathrm{~m} \\
\text { at birth: }\end{array}$ & $\begin{array}{l}12 \mathrm{~m} \\
\text { at birth: }\end{array}$ \\
\hline BW & +0.31 & +0.23 & +0.28 & +0.34 \\
\hline BMI & +0.13 & +0.22 & +0.25 & +0.21 \\
\hline Head length:BW & -0.33 & -0.23 & -0.30 & $-0.65^{b}$ \\
\hline Head length:AC & -0.21 & +0.02 & +0.06 & $-0.70^{c}$ \\
\hline $\mathrm{CW}$ & $\begin{array}{l}\text { at } 3 \mathrm{~m} \text { : } \\
-0.02\end{array}$ & $\begin{array}{l}\text { at } 12 \mathrm{~m}: \\
+0.32\end{array}$ & $\begin{array}{l}\text { at } 3 \mathrm{~m}: \\
+0.03\end{array}$ & $\begin{array}{l}\text { at } 12 \mathrm{~m}: \\
+0.31\end{array}$ \\
\hline BMI & -0.02 & -0.17 & +0.11 & +0.44 \\
\hline Head length:CW & +0.15 & +0.26 & +0.06 & -0.11 \\
\hline Head length:AC & +0.13 & +0.46 & -0.20 & +0.21 \\
\hline GR 0-1 m & +0.28 & $+0.60^{\mathrm{a}}$ & +0.18 & +0.37 \\
\hline GR 0-3 m & +0.03 & $+0.61^{\mathrm{a}}$ & +0.04 & +0.26 \\
\hline GR 0-12 m & - & $+0.55^{\mathrm{a}}$ & - & +0.44 \\
\hline FGR $0-1 \mathrm{~m}$ & +0.04 & $+0.73^{a}$ & -0.09 & +0.20 \\
\hline FGR 1-3 m & -0.22 & +0.04 & -0.15 & -0.36 \\
\hline FGR 3-12 m & - & $-0.51^{\mathrm{a}}$ & - & -0.22 \\
\hline
\end{tabular}

a $p<0.05 ;{ }^{\mathrm{b}} p<0.01 ;{ }^{\mathrm{c}} p<0.005$

At 3 months: $n=25$; at 12 months: $n=15$

Hepatic gluconeogenic enzymes. At 3 months of age, there were no differences in hepatic G6Pase activity (low BW: $79 \pm 6$ units/g protein; high BW: $90 \pm 5$ units/g protein) or PEPCK activity (low BW: $99 \pm 4$ units/g protein; high BW: $89 \pm 9$ units/g protein) between low and high BW pigs (Table 4).

At 12 months of age, there were also no differences in hepatic G6Pase activity (low BW: $83 \pm 6$ units/g protein, high BW: $88 \pm 4$ units/g protein) or PEPCK activity (low BW: $94 \pm 4$ units/g protein; high BW: $97 \pm 3$ units/g protein). G6Pase activity was positively associated with GRs (birth to 1 month, birth to 3 months, birth to 12 months) and fractional GR (birth to 1 month) and negatively associated with fractional GR (3 to 12 months; Table 4). PEPCK activity at 12 months of age was negatively correlated with disproportionate body shape at birth (Table 4).

Hepatic protein content was not different in low and high BW at 3 months (low BW: $145 \pm 4 \mathrm{mg}$ protein/g tissue; high BW: $150 \pm 5 \mathrm{mg}$ protein/g tissue) or at 12 months (low BW: $150 \pm 4 \mathrm{mg}$ protein/g tissue; high BW: $162 \pm 3 \mathrm{mg}$ protein/g tissue). There were no effects of age or group on hepatic G6Pase activity, PEPCK activity or protein content (2 way ANOVA).

\section{Discussion}

This study has shown that low BW in pigs, within the natural range of BWs, is associated with poor glucose tolerance in adult life. Glucose intolerance in adult 
pigs was also associated with low BMI and disproportionate body shape at birth. These findings are consistent with the human epidemiological observations that showed an increased risk of glucose intolerance, insulin resistance and Type II diabetes in adults who were small and thin at birth, but within the normal BW range $[1,2]$. Adult glucose tolerance therefore varies continuously across the entire range of normal BWs in both humans and pigs.

Poor glucose tolerance, measured as an increase in the area under the glucose curve after glucose administration and a longer glucose half-life, was observed in low BW pigs at 12 months, but not at 3 months of age. Age-dependent changes in glucose tolerance have also been observed in other species in which low BW has been induced experimentally [6]. The offspring of rat dams fed on a low-protein diet during pregnancy show improved glucose tolerance in early adult life $[11,12]$ but impaired glucose tolerance by old age [11]. Similarly, in a study of twin lambs of discordant birth weight, glucose tolerance was greater in low BW rather than high $\mathrm{BW}$ lambs during rapid growth in juvenile life, but was not different once body weight gain had stabilised at 12 months of age [13]. In our study, glucose AUC at 3 months was not related to BW or body shape at birth and there was no evidence of improved glucose tolerance in juvenile pigs of low BW. Preliminary observations in guinea pigs naturally growth-retarded in utero indicate that, in common with our study, glucose tolerance is impaired in old, but not young, adults. In humans however, poor glucose tolerance has been linked to low BW and thinness at birth in children and young adults $[14,15,16]$ as well as in older age groups [2]. Despite the range of different experimental approaches, a common feature of all these studies is an association between abnormal glucose tolerance and low BW, particularly when coupled with disproportionate shape at birth.

At 12 months, the body weight of low BW pigs was no longer different from their high BW littermates, due to the increased fractional growth rate very early in postnatal life during suckling, and then again between 3 and 12 months of age. This 'catch up' growth in the first month of life was also directly associated with impaired glucose tolerance at 12 months of age. Poor glucose tolerance in children that were of low BW $[14,15]$ has also been associated with rapid postnatal weight gain in childhood [17]. Rapid postnatal catch up growth of low BW pigs, as a result of good postnatal nutrition, might therefore be as important as impaired intrauterine growth in determining adult glucose tolerance. In humans, low BW and rapid catch up growth is often linked to obesity [18], which, in turn, is a risk factor for adult glucose intolerance. Back fat depth at 12 months of age was greater in the low rather than high BW pigs [19] but was not related to any of the indices of glucose tolerance or insulin secretion shown here.
The mechanisms whereby impaired intrauterine growth programmes the subsequent development of glucose intolerance remain unclear. Both deficiency in insulin secretion and resistance to its action are thought to be involved in the aetiology of poor glucose tolerance and Type II diabetes (see [20]). Naturally occurring low $\mathrm{BW}$ in pigs was associated with reduced basal insulin concentrations at 12 months of age, however a greater insulin response to glucose administration in low BW pigs suggests that their glucose intolerance in adulthood is not due to reduced insulin secretion. In humans, the effects of low BW on adult glucose tolerance are thought to be associated more with insulin resistance rather than insulin deficiency. Fasting hyperglycaemia and increases in the ratios of fasting plasma insulin to glucose concentrations, or insulin AUC to glucose AUC after a glucose load, have all been used as indices of insulin resistance. In our study, however, there was no evidence of insulin resistance using these indices, because low BW and glucose intolerance at 12 months were associated with low basal glucose concentrations and a reduced basal insulin to glucose ratio. However, low BMI at birth was associated with a reduced insulin AUC to glucose AUC ratio at 3 months of age, suggesting increased insulin sensitivity, although there were no indications of altered glucose handling during the GTT at this younger age.

The effect of low BW on adult glucose intolerance could also be associated with abnormalities in glucose production. In adult offspring from protein-deprived pregnant rats, the inhibitory action of insulin on hepatic glucose output is lost [21] and hepatic activities of the key gluconeogenic enzymes, G6Pase and PEPCK, are increased [22]. Impaired glucose tolerance in low BW pigs at 12 months of age might therefore be due, in part, to insulin insensitivity of the hepatic glucogenic pathways and continued glucogenesis during the glucose challenge. However, changes in gluconeogenic enzymes activities are not likely to contribute to this glucose intolerance as hepatic activities of G6Pase and PEPCK were not affected by BW in adult pigs. Indeed, the low basal glucose concentrations in the low BW pigs at 12 months of age suggests that glucogenesis is impaired rather than enhanced in these animals, at least during fasting conditions. Although BW seemed to have little effect on gluconeogenic enzyme activities in adult porcine liver, G6Pase and PEPCK activities were low in 12 month old pigs that were of disproportionate shape at birth and that showed poor early postnatal growth with rapid catch up growth thereafter. In rats, postnatal weight gain has also been shown to influence the increment in hepatic gluconeogenic enzyme activities induced by prenatal protein deprivation [23]. These observations suggest that it is the combination of intrauterine and postnatal growth patterns, possibly in association with the specific prenatal nutrient deficit, that affects hepatic gluconeogenic enzyme activities and glucose production in later life. 
In conclusion, this study has shown that glucose tolerance is impaired in pigs that were small and thin at birth. This effect was observed within the natural range of BWs in pigs and was also associated with postnatal catch up growth. Low BW was not associated with a deficiency in insulin secretion in response to glucose administration. Gluconeogenic enzyme activities in adult porcine liver were also related to disproportionate body shape at birth and to the postnatal pattern of growth, but were not likely to have contributed to the associations observed between BW and adult glucose tolerance in this study. The pig is therefore a useful model for the investigation of the intrauterine origins of abnormalities in adult glucose metabolism.

Acknowledgements. This work is supported by The Wellcome Trust. We are grateful to Paul Hughes for surgical assistance and Sue Nichols and Vicky Johnson for care of the animals.

\section{References}

1. Hales CN, Barker DJ, Clark PM et al. (1991) Fetal and infant growth and impaired glucose tolerance at age 64. BMJ 303:1019-1022

2. Phillips DI, Barker DJ, Hales CN, Hirst S, Osmond C (1994) Thinness at birth and insulin resistance in adult life. Diabetologia 37:150-154

3. Barker DJ (1998) In utero programming of chronic disease. Clin Sci (Colch) 95:115-128

4. Hales CN, Barker DJP (1992) Type II (non-insulin-dependent) diabetes mellitus: the thrifty phenotype hypothesis. Diabetologia 35:595-601

5. Hoet JJ, Hanson MA (1999) Intrauterine nutrition: its importance during critical periods for cardiovascular and endocrine development. J Physiol 514:617-627

6. Ozanne SE, Hales CN (1999) The long-term consequences of intra-uterine protein malnutrition for glucose metabolism. Proc Nutr Soc 58:615-619

7. Poore KR, Fowden AL (2000) Effect of birth weight on glucose tolerance in pigs at 3 and 12 months of age. J Physiol (Lond) 528.P (Abstract)

8. Agricultural and Food Research Council (1990) Technical committee on response to nutrients, Report No. 4, Nutrient Requirements of sows and boars. Nutr Abstr Rev 60:383406
9. Fowden AL, Mijovic J, Silver M (1993) The effects of cortisol on hepatic and renal gluconeogenic enzyme activities in the sheep fetus during late gestation. J Endocrinol 137:213-222

10. Lowry O, Rosenbrough N, Farr A, Randall R (1951) Protein measurement with folin-phenol reagent. J Biol Chem 193:267-275

11. Hales CN, Desai M, Ozanne SE, Crowther NJ (1996) Fishing in the stream of diabetes: from measuring insulin to the control of fetal organogenesis. Biochem Soc Trans 24:341-350

12. Langley S, Browne R, Jackson A (1994) Altered glucose tolerance in rats exposed to maternal low protein diets in utero. Comp Biochem Physiol 109:223-229

13. Clarke L, Firth K, Heasman L et al. (2000) Influence of relative size at birth on growth and glucose homeostasis in twin lambs during juvenile life. Reprod Fertil Dev 12:69-73

14. Law CM, Gordon GS, Shiell AW, Barker DJ, Hales CN (1995) Thinness at birth and glucose tolerance in sevenyear-old children. Diabet Med 12:24-29

15. Hofman PL, Cutfield WS, Robinson EM et al. (1997) Insulin resistance in short children with intrauterine growth retardation. J Clin Endocrinol Metab 82:402-406

16. Robinson S, Walton RJ, Clark PM, Barker DJP, Hales CN, Osmond C (1992) The relation of fetal growth to plasma glucose in young men. Diabetologia 35:444-446

17. Crowther NJ, Cameron N, Trusler J, Gray IP (1998) Association between poor glucose tolerance and rapid post natal weight gain in seven-year-old children. Diabetologia 41:1163-1167

18. Breier BH, Vickers MH, Ikenasio BA, Chan KY, Wong WPS (2001) Fetal programming of appetite and obesity. Mol Cell Endocrinol 185:73-79

19. Poore KR, Fowden AL (2001) Insulin sensitivity, plasma leptin and body fat in 3 and 12 month old pigs of varying birth weight. J Physiol (Lond) 539.P (Abstract)

20. Leahy JL (1990) Natural history of beta-cell dysfunction in NIDDM. Diabetes Care 13:992-1010

21. Ozanne SE, Smith GD, Tikerpae J, Hales CN (1996) Altered regulation of hepatic glucose output in the male offspring of protein-malnourished rat dams. Am J Physiol 270:E559-E564

22. Desai M, Byrne CD, Zhang J, Petry CJ, Lucas A, Hales CN (1997) Programming of hepatic insulin-sensitive enzymes in offspring of rat dams fed a protein-restricted diet. Am J Physiol 272:G1083-G1090

23. Desai M, Byrne CD, Meeran K, Martenz ND, Bloom SR, Hales CN (1997) Regulation of hepatic enzymes and insulin levels in offspring of rat dams fed a reduced-protein diet. Am J Physiol 273:G899-G904 